Jurnal IImiah AL-Jauhari (JIAJ)

Volume 4 No 1, (Juni 2019): 194-218

p-ISSN: 2541-3430

e-ISSN: $2541-3449$

Website: http://journal.iaingorontalo.ac.id/index.php/aj

\title{
Puncak Kulminasi dalam Dunia Tasawwuf: Sebuah Kajian Sufistik
}

\section{Hairuddin}

(IAIN Sultan Amai, Gorontalo)

arman.atho@gmail.com

\begin{abstract}
This article discusses the world of tasawwuf and its ins and outs. This article uses the Library Study method with a Descriptive Historical Qualitative approach. As for the main sources in writing this article are references which include the discussion of Sufis and tasawwuf. The author concluded that Sufism was born of various factors with the aim of approaching the khalik after going through several stages and riyadhah. The culmination of the servant's approach to khalik will give birth: al-Fana, al-Baqa, al-Ittihad, al-Hulul, and Wihdatul Wujud known as the culmination of the culmination.
\end{abstract}

\begin{abstract}
Abstrak
Artikel ini membahas dunia tasawwuf dan seluk beluknya. Artikel ini menggunakan metode Kajian Pustaka dengan pendekatan Kualitatif Historis Deskriftif. Adapun yang menjadi sumber utama dalam penulisan artikel ini adalah referensi-referensi yang memuat pembahasan sufi dan tasawwuf. Penulis berkesimpulan bahwa ajaran tasawuf lahir dari berbagai faktor dengan tujuan melakukan pendekatan kepada sang khalik setelah melalui beberapa tahapan dan riyadhah. Puncak pendekatan hamba kepada khalik akan melahirkan: al-Fana, al-Baqa, al-Ittihad, al-Hulul, dan Wihdatul Wujud yang dikenal dengan puncak kulminasi.
\end{abstract}

Kata Kunci: Maqāmāt; Sufi; Kulminasi 


\section{Pendahuluan}

Dalam Islam, berkembang Ilmu Kalam, Fiqhi, dan kemudian Ilmu Tasawuf. Para tokohnya silang pendapat dalam wacana keislaman yang membawa kepada konflik internal umat Islam. Konflik ini, seharusnya tidak terjadi karena sumbernya sama, yaitu alQur'an dan al-Hadis. Akan tetapi realitas sejarahnya, konflik ini terjadi sehingga sangat merugikan umat Islam pada satu sisi dan di sisi lain mendatangkan manfaat. Mengapa hal yang demikian ini terjadi.

Antara ulama Kalam, Syari'ah dan Tasawuf, telah terjadi perbedaan paradigma terhadap hakekat sesuatu yang ada di alam raya ini. Namun demikian, mereka sepakat bahwa hakekat kebenaran ini hanya satu, yaitu Allah Yang Maha Esa, Maha Kuasa, dan sifatsifatnya yang serba Maha.Ulama kalam dan Fuqaha, telah mengambil kesimpulan bahwa antara mahluk (manusia) dengan penciptanya (Allah), merupakan dua hal yang berbeda, sehingga menurut mereka tidak mungkin bersatu. Akan tetapi, bagi kaum Sufi itu dapat terjadi dengan melalui beberapa jalan yang panjang dan berliku, yang cukup melelahkan dengan berbagai maqāmāt, di antaranya; al-zuhud, altaubat, al-sabr, al-faqr, al-tawadhu', al-taqwa, al-tawakkal, al-ridha, al-mahabbah, al-ma'rifah, al-baqa' wa al-fana' sampai pada alittihad, al-hulul, dan wihdat al-wujud.

Kesemua maqāmāt tersebut merupakan metode yang ditempuh oleh seorang Sufi untuk sampai ke puncak-puncak capaian sufistik, namun metode yang ditempuhnya antara satu sufi dengan sufi yang lain tidak sama. Bahkan keadaan yang dialami ketika ia berada pada puncak tersebut sangat bervariasi. Syaikh Abdul Qadir al-Jailani misalnya, menuturkan pengalamnnya ketika ia keluar dari Bagdad dan tinggal di Karkh (Persia) selama tujuh tahun. Ia mengatakan: "Pada tahun pertama aku hanya memakan rumput-rumputan dan akar-akaran yang dapat kutemukan dan tidak minum air apa pun. Tahun kedua, aku hanya meminum air tanpa makan sebutir pun makanan, dan tahun ketiga, aku tidak makan, minum ataupun tidur. Aku berjalan telanjang kaki di atas duri dan onak padang pasir dan tidak merasakan suatu apapun. Kapan saja aku melihat sebuah jurang (karang yang terjal) aku memanjatnya, aku tidak memberikan istirahat satu menitpun atau menyenangkan nafsuku kepada keinginan-keinginan rendah jasmaniku.

Bahkan menambahkan dengan berkata: "selama empat puluh tahun aku tidak pernah tidur malam, aku menjalankan shalat subuh dengan air wudhu yang telah kupergunakan untuk shalat isya. Aku membaca al-Qur'an setiap malam sehingga tidur tidak menyerangnya secara tiba-tiba.Aku berdiri di atas satu kaki danbersandar pada 
diniding dengan satu tangan, aku tidak mengubah posisi tersebut sampai aku telah membaca al-Qur'an seluruhnya.

Sehingga pada suatu ketika ia mendengar suara pada suatu malam, "Wahai Abdul Qadir al-Jailani, engkau sekarang diperkenankan masuk Bagdad. ${ }^{1}$ Demikian perjalanan panjang dan berliku yang dialami seorang sufi dengan melalui latihan fisik tanpa makan, minum dan tidur serta latihan rohaniah untuk melmpuhkan nafsunya yang mengarah kepada kemewahan duniawi.

Dengan melalui maqāmāt tersebut hingga al-fana', maka sifat kemanusiaan (al-nasut) seorang sufi telah melebur dan yang tinggal hanya sifat ketuhanan (al-lahut), pada keadaan seperti ini manusia dapat bersatu dengan Tuhan. Kesatuan manusia dengan Tuhan dalam literature sufi disebut al-ittihad, al-hulul, dan wahdat al-wujud.

Berdasarkan penjelasan di atas maka pokok bahasan yang menjadii kajian dalam artikel ini mencakup: Asal Usul Sufi dan hakikatnya, bagaimana metode yang ditempuh dalam perjalanan seorang Sufi untuk mendekatkan diri kepada Tuhan demi mencapai titik kulminasi?

\section{Asal usul Sufi}

Para ulama sejarah telah sepakat bahwa pemahaman sufi pertama kali tumbuh dan berkembang di kota Bashrah Irak, dimana dari kota tersebut muncul tokoh-tokoh sufi yang terkenal, seperti Ibrahim bin Adham, Rabiah al Adawiyah, Junaid al Bagdadi dan beberapa tokoh sufi lainnya. Hal ini tidak mengherankan karena beberapa ulama Bashrah terkenal zuhud dan ahli ibadah kepada Allah SWT, sehingga ada ungkapan " Fikhinya Kufah dan Ibadahnya Bashrah". Diriwayatkan bahwa Zurarah bin Aufa seorang Qadhi Bashrah ketika

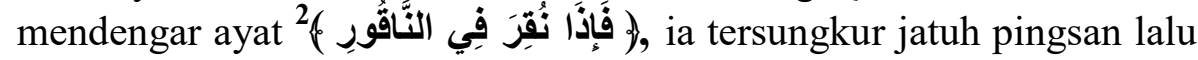
meninggal. Pembicaraan tentang kata sufi muncul pada akhir abad ke III dan awal abad ke IV H, dimana kata tersebut sudah dibahas oleh Ahmad (W 241 H), Abu Sulaiman ad Darani ( W 215 H), Sufyan as Tsauri dan al Hasan al Bashri, hanya saja yang pertama kali sebagai tokoh sufi di masayarakat muslim adalah Abu Hasyim as Sufi (150 $\mathrm{H}){ }^{3}$

${ }^{1}$ Syekh Abdul Qadir al-Jailani, Sirr al-Asrar, diterjemahkan ke dalam bahasa Indonesia oleh Joko S. Kahar dengan judul Rahasia di Balik Rahasia (Cet. 3; Surabaya: Risalah Gusti, 2003), h. xiv-xvi.

${ }^{2}$ Al Muddassir : 8

3 Abu Bakar Ishak al Kalabazi, at Ta'rruf 'ala Mazhab Ahli at Tasawwufi, (Cet. 1; Beirut : Darul Kutub al 'Ilmiyah, 1993), h. 21-26 


\section{Latar belakang Munculnya Sufi}

Mengenai factor-faktor yang menyebabkan lahirya faham sufi ada beberapa pendapat, diantaranya :

\section{Faktor lingkungan alam}

Sebagian peneliti berpendapat bahwa faktor yang menyebabkan munculnya faham sufi adalah faktor lingkungan alam, dan hal itu berawal dari munculnya sekelompok masyarakat yang berusaha meredam sifat hedonisme yang melanda kaum muslim di Irak sebagai akibat dari perluasan wilayah Islam, dan juga karena semakin menjauhnya kaum muslimin dari ajaran Rasulullah dan apa yang dicontohkan oleh para sahabat dan tabi' at tabi'in. Atas dasar ini dapat dipahami bahwa persoalan sufi adalah persoalan yang memiliki akar sejarah yang panjang yang sudah sejak zaman sahabat dan generasi terdahulu, hanya saja menjadi baru kembali karena munculnya beberapa penyimpangan dalam beribadah, dan pendapat ini didukung oleh Ibnu Khaldun dalam Mukaddimahnya. ${ }^{4}$

\section{Penyimpangan dalam Bergama Agama}

Sebahagian ulama menganggap bahwa paham sufi adalah paham keagamaan yang menyimpang, karena pemahaman mereka tentang zuhud tidak seperti lagi yang dipahmi oleh Rasulullah SAW dan para sahabat. Mereka memahami zuhud bukan lagi berhati-hati terhadap kehidupan dunia, tetapi mereka sudah meniggalkan kenikmatan dunia yang hal itu tidak diajarkan oleh Rasulullah, seperti ada diantara mereka menyiksa diri, tidak ingin makan, mengharamkan dirinya mengkonsumsi daging, berwisata ke tempat suci, dan tidak senang menikah. Di Kufah ada seorang ulama yang bernama Ma'dhad bin Yazid al 'Ajeli, ia sengaja melatih diri untuk tidak tidur dan hanya menghususkan diri untuk melaksanakan shalat, ia dan para pengikutnya pergi ke gunung mengkhususkan diri untuk beribadah, meskipun mendapatkan penolakan dari kalangan ulama.

Rasulullah SAW. Ketika mendapatkan laporan bahwa ada seorang sahabat yang shalat lail sepanjang malam, tidak berbuka puasa, dan tidak ingin menikah, Nabi berkata:

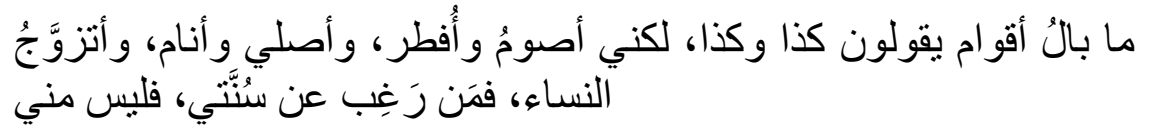

" Ada apa gerangan dengan kaum yang mengatakan : begini, begitu ?, sesungguhnya aku berpusa kemudian berbuka, shalat kemudian tidur, menikahi wanita-wanita, maka barang siapa yang membenci sunnahku bukan dari golonganku". 5

\footnotetext{
4 Abdurrahman Ibnu Khaldun, al Mukaddimah, (Beirut : Maktabah Lubnan, 1992), h. 517

${ }^{5}$ Bukhari Muslim
} 


\section{Syi'ah Persia}

Pendapat ini dinisbatkan kepada kelompok anti sufi dari kalangan sunni. Pendapat ini juga diambil dari tokoh-tokoh yang pernah hidup sezaman dengan para penganut sufi, seperti Abduka singkatan dari Abdul Karim $(\mathrm{W} 210 \mathrm{H})$, ia adalah tokoh Syi'ah yang pertama kali melahirkan paham sufi, dan Abu Hasyim al Kufi as Syi'I as sufi (W $150 \mathrm{H}){ }^{6}$

4. Merupakan pengembangan terhadap agama klasik

Sebagian peneliti berpendapat bahwa paham tasawwuf adalah merupakan perkembangan dari akidah wihadatul wajud irfani yang dianut oleh agama orang timur yang berkembang di Irak, Syam, dan Mesir pada abad ke III SM. Paham wihadatul wajud 'irfani ini adalah hasil perpaduan antara agama asia timur dan agama bangsa Igriqiyah barat yang asal usulnya dari Negara Persia ketika menaklukkkan Irak dan Negara Igriqiyah ketika menaklukkan negeri Syam dan Mesir pada abad ke VI SM. Dengan demikian dapat dipahami paham ini bercampuraduk antara agama Hindu, Budha, dan Kristen.

\section{Hakikat Sufi}

Para ulama sufi berbeda pendapat mengenai asal usul Tasawwuf; ada yang mengatkan dari kata الصفاء yang berarti jernih, ada yang mengatakan dari kata الصوف yang berarti kain wol, ada yang mengatakan dari kata الصفة yang berarti sekelompok sahabat Rasulullah SAW yang pernah tinggal di Masjid yang bertugas membantu pasukan kaum muslimin. ${ }^{7}$ Dan pemahaman Tasawwuf yang benar adalah pemahaman yang lahir dari ilmu yang disertai dengan amal, ditopang dengan sifat Ihsan, keyakinan yang dikuatkan dengan dalil.

Abu Thalib al Makki berkata : " Tasawwuf adalah buah kalimat Tauhid, yang mana ilmunya tidak datang kecuali kepada wali Allah yang ikhlas, hamba allah yang saleh, dengan ilmunya dapat menyingkap rahasia Al quran dan memberi petunjuk kepada jalan yang lurus. Dengan demikian paham Tasawwuf yang benar adalah yang meniti jalan Allah, tekun bertadabbur, banyak berzikir, cinta ilmu, menghindari perdebatan, penuh toleransi, benci kepada yang haram, menjaga amanah, jauh dari perkara syubhat, menolong

\footnotetext{
${ }^{6}$ Kamil Mustafa as syibi, as silah baina at Tasawwuf wa Syi'ah, ( Cet. 3 ; Beirut: Darul Andalus, 1982 ), h. 271

${ }^{7}$ Huda Darwis, At Tasawwuf wa Rasail anNur Li an Nursi, ( Cet. 1; Sozier: Kairo, 2006 ), h. 220. 
kebenaran dan menoloak kebatilan, tidak berbicara dengan batinnya yang bertentangan dengan zahirnya dalam perkara syariat “.

Sayyed Mahmud Abu al Faidh berkata: "Tidaklah dianggap seorang itu sufi sampai ia belajar, dan tidak dianggap mengenal Allah sampai ia beramal, dan tidak dianggap dekat kepada Allah sampai memiliki iman dan akhlak yang rabbani”.

Syekh Abdul Kadir al Jailani berkata: "Jalan yang paling dekat kepada Allah adalah menjaga etika penghambaan, berpegang teguh pada pokok-pokok syariah dan furu'iahnya, dan istiqamah dalam menjaga kualitas takwa".

Dengan demikian hubungan antara Tasawwuf, Syariah, dan Hakikah adalah Syariah itu apa yang keluar dari diri seseorang yang meliputi Wajib, Haram, dan Mubah dimana Syariah adalah tirai yang menutup Hakikat, sedangkan Tasawwuf adalah ruh Syariah dan pancaran Hakikat.

Sayyed Mahmud Abu al fadhil juga pernah berkata: "Siapa yang bodoh terhadap syariah, maka akan menjadi atheis, zindik, dan jauh dari Allah, dan siapa yang menyia-nyiakan Ilmu Ushul akan terhalang untuk sampai kepada tujuan". Jika hal itu terjadi maka, Tasawwuf seperti itu sudah susupi dengan perkara bid'ah dan khurafat yang tidak dikenal oleh para ulama sufi terdahulu dan tidak dibenatrkan oleh Syariat. Dengan penjelasan para ulama sufi dapat ditarik kesimpulam bahwa : "Tasawwuf adalah bentuk cara beribadah yang dibuat untuk menerangi hati, mendidik jiwa, dan membersihkannya dari sifat-sifat tercela, serta menghiasinya dengan sifat-sifat terpuji dalam meniti sebuah perjalanan mengenal Allah.

\section{Perjalanan seorang sufi untuk mendekatkan diri kepada Tuhan}

Realitas penjelajahan kaum sufi telah melahirkan beberapa konsep, pada intinya pada satu tujuan utama yaitu mendekatkan diri kepada Allah (Taqarrub ila Allah). Dasar konsep mereka mengacu pada beberapa ayat al-Qur'an dan hadis Nabi saw., anatar lain Q.S. alBaqarah (2):186.

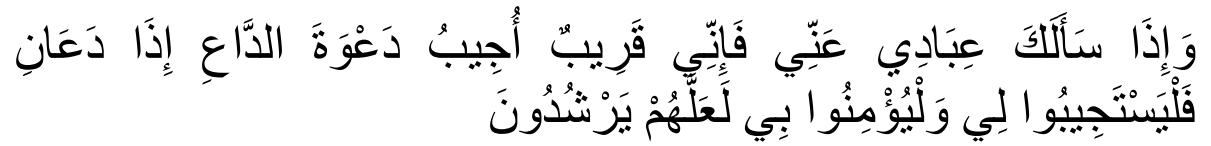

Terjemahnya:

Dan apabila hamba-hamba-Ku bertanya kepadamu tentang Aku, maka (jawablah), bahwasanya Aku adalah dekat. Aku mengabulkan permohonan orang yang berdoa apabila ia memohon kepada- $\mathrm{Ku}$, maka hendaklah mereka itu memenuhi 
(segala perintah-Ku) dan hendaklah mereka beriman kepada-Ku, agar mereka selalu berada dalam kebenaran.

Adapun landasan dari hadis Nabi saw., antara lain hadis yang diriwayatkan oleh al-Bukhari berikut.

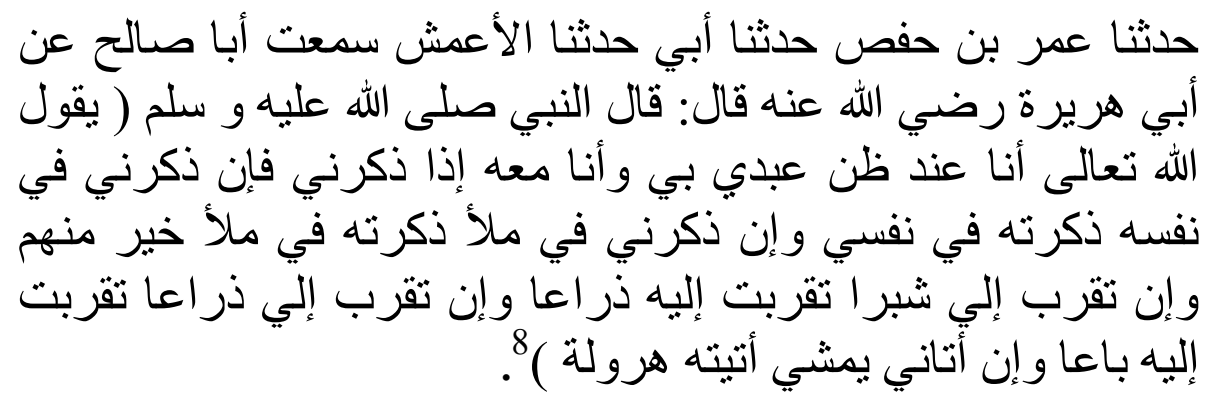

Artinya:

'Umar bin Hafs telah menceritakan kepada kami, Bapakku telah menceritakan kepada kami, al-A'masy telah menceritkakan kepada kami, saya mendengar Aba Shalih, dari Abi Hurairah, dari Nabi saw., beliau bersabda: Allah Ta'ala berfirman Aku sebagaimana persangkaan hambaKu, dan $\mathrm{Aku}$ selalu bersamanya jika ia mengingatKu, maka apabila ia mengingatKu dalam dirinya, maka Aku pun mengingatnya dalam diriKu dan apabila ia mengingatKu dalam perkumpulan maka Aku mengingatnya dalam perkumpulan lebih baik dari mereka, dan jika ia mendekatkan diri kepadaKu sejengkal, maka Aku akan mendekatkan diri kepadanya sehasta, dan jika ia mendekatkan kepadaKu sehasta maka Aku akan mendekatkan diri kepadanya sedepa, dan jika ia mendatangiku dalam keadaan berjalan, maka Aku mendatanginya dalam keadaan berlari.

Tasawuf memang bertujuan agar manusia memperoleh hubungan langsung dengan Allah sehingga ia menyadari benar bahwa dirinya berada sedekat-dekatnya dengan Allah. Namun seorang sufi tidak dapat begitu saja dekat dengan Allah. Ia harus menempuh jalan panjang yang berisi tingkatan-tingkatan. Jumlah maqam yang harus dilalui oleh seorang sufi ternyata bersifat relatife. Artinya, antara satu sufi dengan yang lain mempunyai jumlah maqam yang berbeda karena maqāmāt itu terkait erat dengan pengalaman sufi itu sendiri.

Jalan yang ditempuh oleh seorang sufi (maqāmāt) untuk sampai ketingkat dapat melihat Tuhan dengan mata hatinya dan akhiranya bersatu dengan-Nya sangat panjang dan penuh tantangan. Karena itu hanya sedikit sekali orang yang bisa sampai ke puncak tujuan tasawuf

\footnotetext{
${ }^{8}$ Muhammad bin Ismail bin Abu Abdillah al-Bukhari al-Ja'fi, Al-Jami' alShahih, Jilid 6 (Bairut: Dar Ibn Kasir al-Yamamah, 1407 H/1987 M), h. 2694. 
tersebut. Jalan inilah yang disebut dengan tariqah, ${ }^{9}$ yang secara harfiyyah sebenarnya berarti jalan atau metode.

Dalam literature tasawuf dijelaskan bahwa untuk berada dekat pada Tuhan, seorang sufi harus menempuh jalan panjang yang berisi (maqūmāt). ${ }^{10}$ Maqāmāt yang dimaksudkan adalah sebagai berikut.

\section{Al-Taubah}

Tobat (al-taubah) terdapat dalam Q.S. al-Nur (24):31.

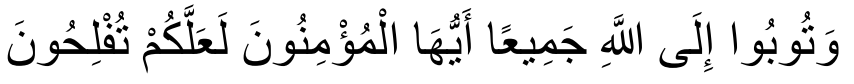

Terjemahnya:

Dan bertaubatlah kamu sekalian kepada Allah, hai orang-orang yang beriman supaya kamu beruntung.

Menurut para sufi dosa adalah pemisah antara seorang hamba dengan Tuhannya karena dosa adalah sesuatu yang kotor, sedangkan Allah Maha Suci dan menyukai kesucian. Karena itu, jika ada orang yang ingin berada sedekat mungkin dengan Allah maka ia harus membersihkan diri dari segala macam dosa dengan jalan tobat. Tobat yang dimaksudkan disini adalah tobat yang sebenarnya, yang tidak melakukan dosa lagi. Bahkan lebih jauh lagi kaum sufi memahami dengan lupa pada segala hal kecuali Allah. Tobat tidak dapat dilakukan hanya sekali, tetapi harus berkali-kali sebagaiman hadis yang berbunyi.

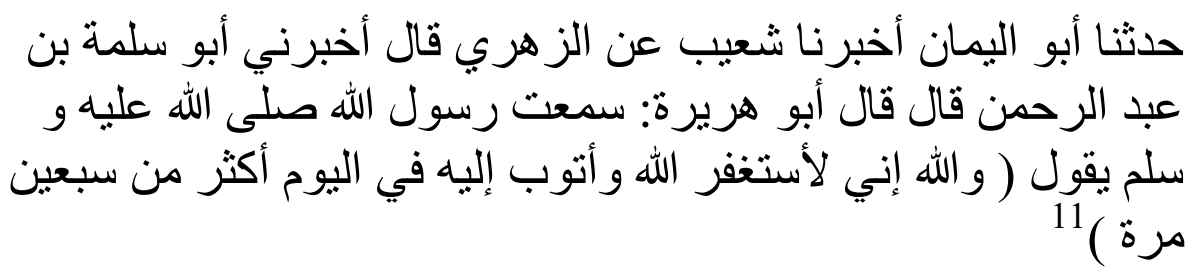

Artinya:

Abu al-Yaman telah menceritakan kepada kami, Syu'bah telah mengabarkan kepada kami dari al-Zuhri ia berkata: Abu

${ }^{9}$ Amin Syukur, Menggugat Tasawuf, Sufisme dan Tanggung Jawab Sosial Abad 21 (Cet. 2; Yogyakarta: Pustaka Pelajar, 2002), h. 48.

${ }^{10}$ Maqūmāt atau tahapan-tahapan merupakan tingkatan suasana kerohanian yang ditunjukkan oleh seorang sufi. Bentuk maqāmāt adalah pengalamanpengalaman yang dirasakan dan diperoleh seorang sufi melalui usaha-usaha tertentu, jalan panjang berisi tingkatan yang harus ditempuh oleh seorang sufi agar berada sedekat mungkin dengan Allah. Ensiklopedi Islam, Jilid 3 (Jakarta: PT. Ihtiar Baru Van Hoeve, 1994), h. 124.

${ }^{11}$ Muhammad bin Ismail bin Abu Abdillah al-Bukhari al-Ja'fi, Al-Jami' alS\{ahih, Jilid 5 (Bairut: Dar Ibn Kasir al-Yamamah, 1407 H/1987 M), h. 2324 
Salamah bin ABd al-Rahman berkata: Abu Hurairah telah berkata: Saya mendengar Rasulullah saw., bersabda: Demi Allah, sungguh saya beristigfar kepada Allah dan bertobat kepadanya dalam sehari lebih dari tujuh puluh kali.

\section{Al-Wara'}

Warak (wara'), menjauhkan diri dari segala sesuatu yang di dalamnya mengandung syubhat (keraguan) terhadap yang halal karena dengan mendekati syubhat maka seseorang akan terjerumus kepada sesuatu yang haram.

\section{Al-Zuhd}

Zuhud (al-zuhd) adalah keadaan meningalkan dunia dan menjauhkan diri dari kehidupan kebendaan. ${ }^{12}$ Sebagaimana dalam Q.S. al-Nisa' (4):77.

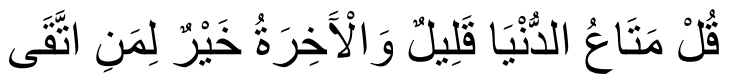

Terjemahnya:

Katakanlah: "Kesenangan di dunia ini hanya sebentar dan akhirat itu lebih baik untuk orang-orang yang bertakwa.

Zuhud bagi kaum sufi adalah maqam terpenting yang harus dilalui. Seseorang yang hendak menjadi seorang sufi harus terlebih dahulu menjadi zahid (asketik) karena menurut mereka, dunia dan segala kehidupan ini merupakan sumber kemaksiatan dan penyebab terjadinya perbuatan-perbuatan yang mendatangkan dosa.

4. Al-Faqr

Kefakiran (al-faqr) ditemukan dalam Q.S. Fat $\}$ ir (35):15.

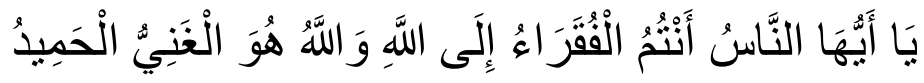

Terjemahnya:

Hai manusia, kamulah yang berkehendak kepada Allah; dan Allah Dialah Yang Maha Kaya (tidak memerlukan sesuatu) lagi Maha Terpuji.

Dalam paham tasawuf berarti senatiasa butuh kepada Allah bukan orang yang tidak punya bekal hidup, tetapi orang yang bersih atau kosong hatinya dari keinginan duniawi. ${ }^{13}$ Seseorang tidak meminta lebih dari apa yang telah ada pada dirinya. Tidak meminta

\footnotetext{
${ }^{12}$ Harun Nasution, Falsafah dan Mistisme dalam Islam (Cet. 9; Jakarta: Bulan Bintang, 1995), h. 65.

${ }^{13}$ Media Zainul Bahri, Menembus Tirai Kesendirian-Nya; Mengurai Maqāmāt dan Ahwal dalam Tradisi Sufi (Cet. 1; Jakarta: Prenada, 2005), h. 63.
} 
rizki kecuali hanya untuk dapat menjalankan kewajibankewajibannya. Namun jika diberi ia terima. Seorang sufi tidak meminta dan menolak pemberian Allah.

5. Al-Sabr

Sabar (al-sabr), dalam Q.S. al-Nahl (16):127.

$$
\text { وَ اصْبِرْ وَمَا صَبْرْ كَ إلَّا بِالَّهِ }
$$

Terjemahnya:

Bersabarlah (hai Muhammad) dan tiadalah kesabaranmu itu melainkan dengan pertolongan Allah.

Sabar merupakan suatu pekerti yang dapat dibentuk oleh seseorang.Ia menahan nafsu dari putus asa, sedih dan simentil. Ia menahan jiwa dai kemarahan, menahan lidah dari merintih kesakitan, dan anggota badan dari melakukan sesuatu yang tidak pantas. Sabar merupakan ketegaran hati atas hukum takdir dan hukum-hukum syariat. ${ }^{14}$ Sabar yaitu konsekwen dan konsisten melaksanakan semua perintah Allah dan menjauhi larangannya, tahan uji menhadapi kesulitan dan cobaan, tabah menunggu datangnya pertolongan Allah dan tabah menerima segala konsekuensi atas kesabarannya.

\section{Al-Tawakkal}

Tawakkal (al-Tawakkul), yaitu menyerahkan diri secara total kepada Allah. ${ }^{15}$ Dalam Q.S. al-Talaq (65):3.

$$
\text { وَمَنْ بَتَوَكَّنْ عَلَى اللَّهِ فَهُوَ حَنْبُهُ }
$$

Terjemahnya:

Dan barangsiapa yang bertawakkal kepada Allah niscaya Allah akan mencukupkan (keperluan)nya.

Tawakkal berhubungan dengan nilai kesempurnaan batin seorang sufi karena menyadari bahwa Allah bertindak sesuai dengan kehendaknya. Ia menyerahkan diri tanpa bertanya sebab-sebabnya dan meninggalkan usaha di luar batas kemampuannya sebagai manusia.

7. Al-Rida

${ }^{14}$ Ibnu Qayyim al-Jauziyah, al-Faruqun Nafisah baina Sifatinnafsi alTayyibah wa al-Khabisah. Diterjemahkan oleh Abu Ahmad Najieh dengan judul Etika Kesucian: Wacana Penyucian Jiwa, Entitas sikap hidup Muslim(Cet. 1; Surabaya: Risalah Gusti, 1998), h. 30.

${ }^{15}$ Abi Qasim Ab al-Karim bin Hauzan al-Qusairi, al-Risalah al-Qusairiyyah (Cet. 5; Baeirut: Dar al-Kutub al-Ilmiyyah, 2005), h. 199. 
Rida (al-Rida), yaitu menerima qada dan qadar Allah serta mengeluarkan rasa benci sehingga yang tinggal adalah rasa senang, dan tidak meminta imbalan atas amal ibadahnya, dan lebih dari itu merasa senang jika tertimpa musibah sebagaimana ia senag ketika menerima nikmat.

\section{Al-Mahabbah}

Cinta (al-mahabbah).Cinta kepada Allah dalam arti patuh kepada-Nya, membenci setiap sikap yang melawan kepada-Nya, menyerahkan diri sepenuhnya dan mengosongkan diri dari segalanya kecuali Allah yang dicintai. Maqam mahabbah ini didasarkan pada surat al-Maidah ayat 54 dan Ali Imran ayat 31.

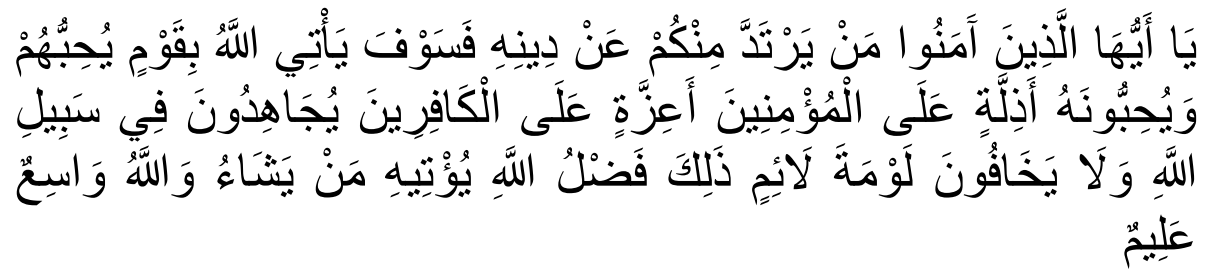

Terjemahnya:

Hai orang-orang yang beriman, barangsiapa di antara kamu yang murtad dari agamanya, maka kelak Allah akan mendatangkan suatu kaum yang Allah mencintai mereka dan merekapun mencintaiNya, yang bersikap lemah lembut terhadap orang yang mukmin, yang bersikap keras terhadap orang-orang kafir, yang berjihad dijalan Allah, dan yang tidak takut kepada celaan orang yang suka mencela. Itulah karunia Allah, diberikan-Nya kepada siapa yang dikehendaki-Nya, dan Allah Maha Luas (pemberian-Nya), lagi Maha Mengetahui.

Tokoh yang paling populer bagi maqam ini adalah Rabiah al Adawiyah . Ia wanita yang banyak beribadah dan khusyu. Ia Tidak tergoda kehidupan duniawi. Hatinya hanya tertuju kepada Allah, ia tenggelam dalam cintanya kepada Allah SWT dan beramal demi keridhaan Nya . Tidak ada sesuatupun yang memalingkan hidupnya dari mengingat Allah. Id selalu melakukan sholat tahajjud sepanjnag malan hingga fajar tiba. Ia dikenal sebagai seorang wanita yang berpaham Mahabbah (cinta ). Baginya Allah adalah Zat yang dicintai dan rasa cintanya mendalam hanya kepada Allah. Oleh karena itu , dia mengabdi dan melakukan amal saleh bukan karena takut masuk neraka, atau mengharap masuk surge, tetapi karena cinta kepada Allah. Pendek kata, Allah baginya merupaka Zat yang sangat dicintai, buka Zat yang harus ditakuti. Ia pernah melantunkan sebuah puisi: 


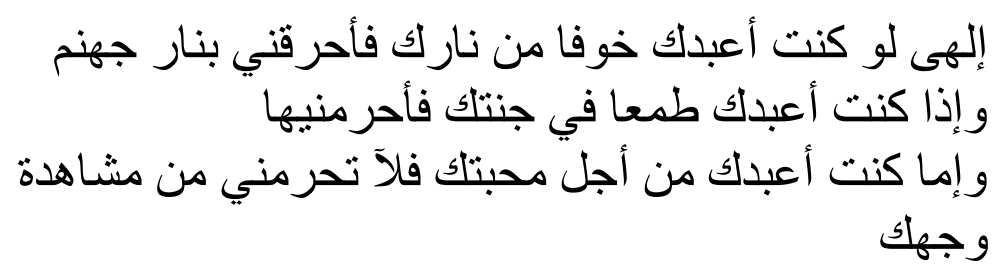

"Wahai, Tuhan! Apabika aku beribadah kepada-Mu hanya karena takut kepada neraka-Mu maka bakarlah aku dengan neraka-Mu. Dan apabila aku beribadah kepada-Mu hanya menginginkan surga-Mu maka keluarkanlah aku dari surga-Mu. Tetapi, jika aku beribadah kepada-Mu hanya untuk-Mu semata, berikanlah kepadaku keindahan-Mu yang abadi." 16

\section{Al-Ma'rifah}

Makrifat (al-ma'rifah).Mengetahui Allah dari dekat sehingga hati sanubari dapat melihatnya. ${ }^{17}$ Dalam kitab Risalah al-Qusyairiah sebagaimana yang dkiutip oleh Mustafa Zahri dimana imam Abi Qasim $^{18}$ berkata:

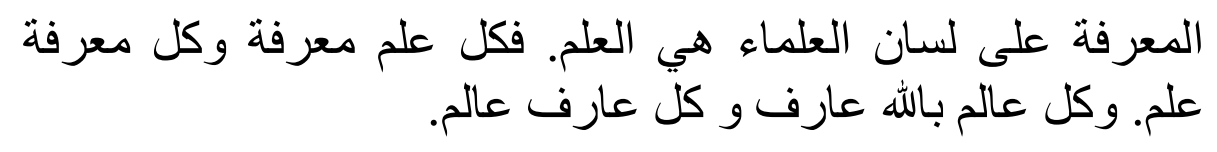

Artinya:

Arti makrifat menurut pendapat ulama (bukan ahli tasawuf) ialah pengetahuan, maka tiap-tiap ilmu adalah makrifat, dan tiap-tiap makrifat adalah ilmu. Dan tiap-tiap 'alim tentang Allah, adalah orang 'arif dan tiap-tiap 'arif adalah 'alim.

Selanjutnya memberikan perincian tentang pengertian makrifat ${ }^{19}$ sebagai berikut:

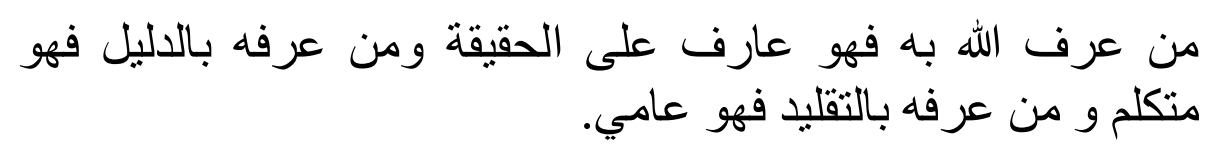

Artinya:

Barangsiapa mengenal Allah dengan jalan pertolongan Allah, maka orang itu adalah 'Arif tentang Allah secara hakekat (ahli

\footnotetext{
${ }^{16}$ Muhammad bin Jamil Zainu, Aiaran Sufi dan Tarekat, ( Cet. 2 ; Jakarta : Darul Haq, 2015 ), h. 11

${ }^{17}$ Harun Nasution, Falsafat dan Mistisme dalam Islam, h. 75.

${ }^{18}$ Mustafa Zahri, Kunci Memahami Ilmu Tasawuf (Surabaya: PT. Bina Ilmu, t.th.), h. 165-166.

${ }^{19}$ Mustafa Zahri, Kunci Memahami Ilmu Tasawuf, h. 166
}

Jurnal IImiah AL-Jauhari Volume 4 No 1, (Juni 2019): 194-218 | 205 
tasawuf). Orang yang arif tentang Allah dengan cara dalil saja maka itu, adalah Mutakallimin (Ahli Ushuluddin). Orang yang Arif tentang Allah dengan cara taklid (menuruti perkataan tanpa mencari ilmu) maka orang itu adalah orang awam/bodoh.

Selanjutnya dalam tasawuf Zhunnun al-Misriyah (w. $860 \mathrm{M}$ ) yang dipandang sebagai bapak paham Makrifat. Menurut beliau ada tiga macam pengetahuan tentang Tuhan, ${ }^{20}$ yaitu:

1. Pengetahuan awam: Tuhan satu dengan perantaraan ucapan syahadat.

2. Pengetahuan Ulama: Tuhan satu menurut jalan akal pikiran.

3. Pengetahuan Sufi/Tasawwuf: Tuhan satu dengan penglihatan Hati sanubari.

Pengetahuan menurut pengertian pertama dan kedua, belum merupakan pengetahuan hakiki tentang Tuhan. Keduanya disebut ilmu bukan makrifat. Pengetahuan menurut pengertian ketigalah yang merupakan pengetahuan hakiki tentang Tuhan dan pengetahuan ini disebut makrifat.

Makrifat hanya terdapat pada kaum sufi, yang sanggup melihat Tuan dengan hati sanubarinya. Pengetahuan serupa ini hanya diberikan Tuhan kepada kaum sufi yang sangat berhasrat untuk menemukan Tuhan karena sangat cintanya kepada-Nya. Makrifat dimasukkan Tuhan ke dalam hati seorang sufi. Sehingga hatinya penuh dengan cahaya. Ketika Zhunnun ditanya tentang bagaimana ia memperoleh makrifat Tuhan ia menjawab:

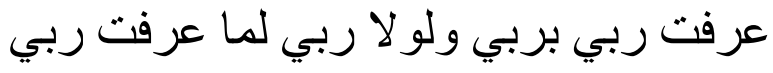

Artinya:

Aku mengenal Tuhan dengan pertolongan Tuhanku, dan sekiranya tidak karena Tuhanku aku tidak akan kenal Tuhanku.

Ini mengambarkan bahwa makrifat tidak diperoleh begitu saja, akan tetapi adalah pemberian dari Tuhan. Karena itu maka makrifat bukanlah hasil pemikiran manusia, tetapi bergantung kepada kehendak dan rahmat Tuhan, dalam arti bahwa makrifat adalah pemberian Tuhan kepada kaum Sufi yang sanggup menerimanya.

Alat untuk memeperoleh makrifat oleh kaum Sufi disebut sir.Dalam Risalah al-Qusyairiyah disebutkan ada tiga alat dalam tubuh

\footnotetext{
${ }^{20}$ Mustafa Zahri, Kunci Memahami Ilmu Tasawuf, h. 166
} 
manusia yang dipergunakan orang Sufi dalam hubungan mereka dengan Tuhan. ${ }^{21}$

1. Qalb: untuk mengenal sifat-sifat Tuhan.

2. Ruh: untuk mencintai Tuhan.

3. Sirr: untuk melihat Tuhan.

Sirr lebih halus dari ruh dan ruh lebih halus dari qalb. Qalb tidak sama dengan jantung, karena qalb selain alat untuk merasa adalah juga alat untuk berfikir. Perbedaan akal dengan qalb ialah bahwa akal tidak bisa memperoleh pengetahuan yang sebenarnya tentang Tuhan, sedangkan qalb bisa mengetahui hakekat dari segela yang ada dan jika Tuhan melimpahkan cahaya-Nya kepada Qalb, bisa ia mengetahui segala yang diketahui Allah.

Sirr bertempat di ruh dan ruh bertempat di qalb. Sirr timbul dan dapat menerima rahmat dari Allah kalau qalb dan ruh itu telah suci sesuci-sucinya, kosong tidak berisi apapun. Pada ketika itulah Tuhan menurunkan cahaya-Nya kepada sang Sufi dan yang dilihat oleh sang Sufi itu hanyalah Allah. Ketika itulah ia telah sampai ke tingkat Makrifat.

Disamping maqāmāt terdapat juga ahwal merupakan istilah tasawuf yang berarti "suatu keadaan mental"., jika maqam adalah merupakan tingkatan sikap hidup yang dapat dilihat dari perbuatan seseorang, maka hal adalah kondisi mental yang sifatnya abstrak. Ia tak dapat dilihat tetapi dapat dipahami dan dirasakan oleh orang yang mengalaminyadan karenanya sulit diungkapkan dengan kata-kata. Maqam dapat dicapai seseorang dengan kehendak dan upayanya.Sementara hal dapat diperoleh seseorang tanpa disengaja.Namun perlu dicatat, maqam dan hal tak dapat dipisahkan.Keduanya ibarat dua sisi dalam satu mata uang. Keterkaitan keduanya dapat dilihat dalam kenyataan bahwa maqam menjadi prasyarat menuju Tuhan; dan dalam maqamakan ditemukan keadaan hal. Hal yang telah ditemukan dalam maqam akan mengantarkan seseorang untuk mendaki maqam-maqam selanjutnya.

Sekedar sebagai contoh, seseorang yang tengah berada dalam maqam tobat akan menemukan hal (perasaan) betapa indahnya bertobat dan betapa nikmatnya menyadari dosa-dosa di hadapan Tuhan. Perasaan ini akan menjadi benteng kuat untuk tidak mengerjakan kembali dosa yang pernah dilakukan. Sebagaimana halnya maqam, kaum sufi juga berbeda pendapat mengenai jumlah dan formasi hal. Diantara sekian banyak nama dan sifat hal yang terkenal adalah muraqabah, al-kahuf, al-raja', al-syauq, al-uns, altuma'ninah, dan al-yaqin.

${ }^{21}$ Mustafa Zuhri, Kunci Memahami Ilmu Tasawuf, h. 167. 


\section{Muraqabah}

Muraqabah adalah salah satu sikap mental yang mengandung pengertian adanya kesadaran diri bahwa ia selalu berhadapan dengan Allah dan merasa diri selalu diawasi oleh penciptanya. Jadi sikap mental muraqabah ini merupakan suatu sikap yang selalu memandang Allah denan mata hatinya, sebaliknya ia pun sadar bahwa Allah selalu memandang kepadanya dengan penuh perhatian. Orang yang berada pada kondisi mental seperti ini akan selalu berusaha menata dan membina kesucian dirinya. ${ }^{22}$

\section{Al-khauf}

Al-khauf adalah suatu sikap mental mersa takut kepada Allah karena kurang sempurna pengabdiannya atau rasa takut dan khawatir jangan sampai Allah merasa tak senang kepadanya.Rasa takut bermula ketika jiwa mendekati langkah pertama dalam jalan mistik. Rasa takut ini terasa sangat berat ketika menghadapi sesuatu yang baru, yang akan dilaluinya, karena ia tak terbiasa dengannya. ${ }^{23}$ Dengan sikap itu, yang bersangkutan melakukan pelbagai amal terpuji dan menjauhi perbuatan yang keji.

\section{Al-raja'}

Al-Raja' adalah suatu sikap optimis dalam memperolah karunia dan nikmat Allah yang disediakan pasti akan datang. ${ }^{24}$ Ia menyadari bahwa Allah itu Maha Pemurah, Maha Penyayang dan Maha Pemaaf, sehingga dalam dirinya timbul rasa optimis yang besar untuk melakukan berbagai amal terpuji guna mewujudkan harapanharapannya itu.

Raja' menuntut tiga perkara, yaitu:

a. Cinta kepada apa yang diharapkannya.

b. Takut bila harapannya hilang.

c. Berusaha untuk mencapainya.

4. Al-syauq

al-Syauq (rasa rindu) adalah suasana kejiwaan yang menyertai mahabbah (perasaan kasih sayang). Rasa rindu ini memancar dari kalbu karena gelora cinta yang murni. Pengetahuan dan pengenalan

${ }^{22}$ Media Zainul Bahri, Menembus Tirai Kesendirian-Nya; Mengurai Maqāmāt dan Ahwal dalam Tradisi Sufi., h. 83-86

${ }^{23}$ Hassan Hanafi, Islam in Modern World, diterjemahkan oleh Munirul Abidin dengan judul Rekonstruksi Pemahaman Tradisi Islam Klasik (Cet. 1; Malang: Kutub Minar, 2004), h. 50.

${ }^{24}$ Abi Qasim abd al-Karim bin Hauzan al-Qusyairi, ar Risalah al Qusyairiyah, h. 168 
yang lebih mendalam akan menimblkan rasa senang dan ghairah yang besar untuk selalu bersama-sama dengan Tuhannya pada setiap denyut jantungnya.

\section{Al-uns}

Al- Uns yang berarti keakraban atau keintiman bisa juga berarti hati yang terhibur dan senang ketika menyaksikan keindahan. ${ }^{25}$ Rasa berteman yang akrab dengan Allah yang menimbulkan kegembiraan Karena tersingkapnya keindahan rahasia Ilahi yang belum pernah ia lihat sehingga seluruh ekspresi jiwanya terpusat penuh pada satu titik, yaitu Allah. Tidak ada yang dirasa, dan yang diharap selain Allah.Segenap jiwa dan perhatiannya terpusat pada Allah sehingga dirinya seolah-olah telah hilang. Menurut DZhunnunn Al-Misri, orang yang seperti ini sungguhpun dilempar ke dalam api Neraka, ia tak akan merasakan panasnya. Menurut al-Junaid, tokoh tasawuf yang lebih modern, orang yang seperti itu sekalipun dibelah dengan pedang ia tak lagi merasakannya.

Seseorang yang merasakan Ush dibedakan menjadi tiga kondisi. Pertama, hamba yang suka merasakan suka cita berzikir menginggat Allah dan merasakan gelisa disaat lalai. Kedua, seorang hamba yang senang dengan Allah dan gelisah terhadap bisikan hati, dsb. Ketiga, yaitu kondisi yang tidak melihat lagi suka cita karena adanya wibawa kedekatan kemuliaan dan mengagungkan disertai dengan suka cita. ${ }^{26}$

\section{Al-tuma'ninah}

Al-tuma'ninah berarti tenang dan tentram. Orang yang mencapai tahap ini tidak memiliki rasa was-was dan khawatir. Tidak ada lagi yang dapat mengganggu perasaan dan pemikirannya karena sudah berhasil mencaoai tingkat kesucian jiwa yang paling linggi.Orang ini dapat berkomunikasi dengan Allah. Karenanya ia merasa sangat senang dan bahagia. Tentu saja semuanya dicapai setelah melalui berbagai perjuangan. $^{27}$

\section{Al-Musyahadah}

\footnotetext{
${ }^{25}$ Media Zainul Bahri, Menembus Tirai Kesendirian-Nya; Mengurai Maqāmāt dan Ahwal dalam Tradisi Sufi., h. 106.

${ }^{26}$ Tim Penyusun MKD Iain Sunan Ampel Surabaya, Akhlak Tasawuf, (Surabaya: IAIN Sunan Ampel Pres. 2011), h. 271

27 Tim Penyusun MKD Iain Sunan Ampel Surabaya, Akhlak Tasawuf.,h. 110-112.
} 
Al-Musyahadah yaitu menyaksikan secara jelas dan sadar apa yang dicarinya itu, dalam hal ini yang dicapai oleh seorang sufi, yaitu Allah. Orang seperti itu merasa seolah-olah sudah tidak ada lagi tabir yang mengitarinya dengan Tuhannya. Sehingga tersingkaplah segala rahasia melalui sir (mata hatinya) mengenai apa yang ada pada Allah.

\section{Al-yaqin}

Al-Yaqin yaitu perpapduan antara pengetahuan yang luas serta mendalam dan rasa cinta serta rindu yang mendalam pula sehingga tertanamlah di dalam jiwanya perjumpaan secara langsung dengan Tuhannya. Pada tingkat ini seseorang memiliki kepercayaan yang kokoh dan tak tergoyahkan tentang kebenaran pengetahuan yang dimilikinya karena ia sendiri menyaksikan dengan segenap jiwanya, dirasakan dengan seluruh ekspresinya, dan dipersaksikan dengan segenap keberadaannya.

Dari uraian maqāmāt dan ahwal di atas, dapat disimpulkan bahwa dasarnya tariqah atau metode sufi untuk mencapai puncakpuncak sufistik dapat difomulasikan kepada tiga tahap, yaitu;

\section{a. Takhalli}

Takhalli yaitu pembersihan diri dari sifat-sifat tercela, kotoran dan penyakit hati yang dirusak. Seorang yang menjalani kehidupan sufi harus menyadari benar tentang hasrat-hasrat (nafsu) keduniaan, berusaha menghindarinya, dan berusaha semaksimal menjaga dirinya dari hal-hal yang mengganggu untuk mengingat Allah swt. ${ }^{28}$

\section{b. Tahalli}

Tahalli, yakni menghias diri dengan jalan membiasakan diri unutk bersifat dan bersikap yang terpuji, berusaha agar setiap gerak dan tingkah lakunya berjalan sesuai dengan ajaran-ajaran agama, dan konsisten dengan langkah-langkah sebelumnya (ber-takhalli) , melakukan olah fisik (riyadah) dan jiwa dengan amalan-amalan baik (ibadah). ${ }^{29}$

\section{c. Tajalli}

Tajalli adalah apa yang nampak di qalbu dari cahaya-cahaya gaib. ${ }^{30}$ Setelah seseorang melalui dua tahap di atas, maka dia akan

\footnotetext{
${ }^{28}$ Hasan al-Syarqawi, Mu'jam alFaz al-Sufiyyah (Cet. 1; Cairo: Mu'assasah Mukhtar, 1987), h. 75.

${ }^{29}$ Amin Sykur, Menggugat Tasawuf, Sufisme dan Tanggung Jawab Sosial Abad 21, ( Cet. 2; Yogyakarta: Pustaka Pelajar, 2002 ), h. 47.

${ }^{30}$ Abd al-Razzaq al-Kasyani, Mu'jam Istilahat al-Sufiyah, (Cet. 1; Cairo:Dar al-Manar, 1992), h. 173.
} 
berada pada tahap tajalli, hatinya akan terbebeaskan dari tabir yaitu sifat-sifat kemanusiaan atau memperolah nur yang selama ini tersembunyi atau al-fana', segala selain Allah ketika nampak (tahalli) wajah-Nya. $^{31}$

Apabila seorang sufi telah mencapai tingkat tertinggi, tidak berarti selesailah mujahadah atau tamatlah latihannya. Mujahadah itu harus dilakukan terus-menerus sampai ujung perjalanan suluknya.

\section{A. Metode yang ditempuh seorang sufi dalam capaian sufistik}

Dalam literature tasawuf dijelaskan bahwa 'ilm, tafakkur, tazakkur, ma'rifat dan mahabbah merupakan metode untuk mencapai pincak-puncak sufistik. Dengan melalui metode tersebut seorang sufi memungkinkan melakukan pendekatan kepada Allah swt., bahkan dapat menunggal denga Allah swt. metode yang dimaksud adalah sebagai berikut:

\section{Riyadah}

Riyadah yang sering juga disebut sebagai latihan - latihan mistik, adalah latihan melalui kejiwaan upaya membiasakan diri agar tidak melakukan hal-hal yang mengotori jiwa. Riyadah dapat pula proses internalisasi kejiwaan dengan sifat-sifat terpuji dan melatih diri untuk meninggalkan sifat-sifat buruk. ${ }^{32}$

Riyadah harus disertai dengan mujahadah, yaitu kesungguhan dalam usaha untuk meninggalkan sifat-sifat buruk. Meninggalkan sifat-sifat buruk sangat berat sehingga membutuhkan kesungguhan dalan me-riyadah-kannya. Perbedaan antara riyadah dengan mujahadah adalah riyadah buerpa tahapan-tahapan real, sedangkan mujahadah berusaha menekan atau mengendalikan masing-masing tahapan riyadah dengan sungguh-sungguh.

\section{Tafakkur}

Tafakkur dari segi bahasa berarti berfikir.Kata ini berasal dari bahasa Arab "Fikr" yang berarti pikiran. ${ }^{33}$ Kata fikr dalam perkembangannya merupakan perubahan dari fakr yang berarti menggosok. ${ }^{34}$ Sedang tafakur dari segi istilah adalah refleksi atau perenungan terhadap sesuatu.Akar dari seluruh maujud adalah nama-

\footnotetext{
${ }^{31}$ Amin Syukur, Menggugat Tasawuf, Sufisme dan Tanggung Jawab Sosial Abad 21, h. 48.

32 Al-Ghazali, Risalah al-Ladunniyah, Jilid I (Mesir:Maktabah al-Jundi, 1970), h. 122 .

${ }^{33}$ Ahmad Warson, op. cit., h. 1148

${ }^{34}$ Ibid.,h. 62.
} 
nama Allah Yang Maha Indah (al-asma' al-husna).Oleh karena itu, tafakkur berkaitan dengan nama-nama Allah, bukan zat-Nya. ${ }^{35}$

Kedua kata tersebut ada persamaannya, yaitu menggosok, tetapi bedanya ialah kata fakr digunakan untuk menggosok bend kongkrit sedang fikr digunakan untuk menggosok atau menggali hal-hal yang bersifat abstrak, yaitu menggali makna sesuatu untuk mencapai hakikatnya, maksudnya berfikir.

Kemudian Allah memerintahkan kepada manusia berfikir mengenai kehidupan alam, ${ }^{36}$ yang menggambarkan bahwa ala mini diatur olehkekuatan Yang Maha Kuasa, itulah Tuhan.

Disamping itu Allah juga memerintahkan kepada manusia untuk memikirkan dirinya ${ }^{37}$ agar lebih mudah mengerti kekuasaan dan kebesaran Allah. Karena apa yang akan direnungkan akan melekat pada dirinya sendiri.

\section{Tazkiyah al-Nafs}

Tazkiyah al-Nafs adalah proses penyucian jiwa manusia. Proses penyucian jiwa dalam kerangka tasawuf ini dapat dilakukan melalui tahapan takhalli dan tahalli. Tazkiyah al-Nafs merupakan inti kegiatan bertasawuf. Tazkiyah al-Nafs dalam konsepsi tasawuf berdasar pada asumsi bahwa jiwa manusia ibarat cermin, sedangkan ilmu ibarat gambar objek materil.Kegiatan mengetahui ibarat cermin yang menangkap gambar-gambar. Banyaknya gambar yang ditangkap dan jelasnya tangkapan bergantung pada kadar kebersihan cermin. ${ }^{38}$ Dengan demikian kesucian jiwa adalah syarat masuknya hakikat atau ilmu makrifat ke dalam jiwa, sementara jiwa yang kotor membuat manusia terhijab dari Allah.

\section{Tazakkur}

Tafakkur dan tazakkur sama-sama berarti berpikir atau merenung, tetapi ada bedanya, yaitu tafakkur adalah kegiatan berfikir untuk melahirkan sesuatu yang baru.Sedangkan tazakkur berarti

\footnotetext{
${ }^{35}$ Amatullah Amstrong, SufiTerminologi (al-Qamus al-Sufi) The Mystical Language of Islam, diterjemahkan oleh MS. Asrullah dan Ahmad Baiquni dengan judul Khazanah Istilah Sufi Kunci Memasuki Dunia Tasawuf, (Cet. 1; Bandung: Mizan 1996), h. 278.

${ }^{36}$ Memikirkan ciptaan Allah, lhat Q.S. al-Rum(30):8; Ali Imran (3):190191; Q.S. al-Dukhan (44): 38-39; al-Ra'ad(13):3; (Q.S. al-Nahl(16):10-11,68-69; Q.S. al-Jasiyah(45):13.

${ }^{37}$ Lihat, Q.S. Abatasa (80):17-22; al-Rum (30):20; al-Qiyamah (75):37-38; al-Mursalat (77):20-22; Q.S. Yasin (36): 77; al-Insan(76):2; Sn Q.S. al-Mu'minun (23):12-13.

${ }^{38}$ Al-Ghazali, Raudah al-Talibin wa 'Umdah al-Salikin, h. 108.
} 
berfikir untuk mengingat kembali informasi atau pengetahuan yang telah didapat sebelumnya, yang kemudian terlupa dan dilalaikan.

Lupa dan lalai merupakan kondisi pikiran dan jiwa yang sangat berbahaya, karena dapat membuat manusia lupa dan lalai kepada halhal yang sangat penting, yaitu kewajiban kepada Allah dan tanggung jawab kepada sesama manusia.

B. Titik kulminasi capaian sufistik

1. Al-Fana',al-Baqa'dan Al-Ittihad

Al-fana' dan al-Baqa. Dari segi bahasa, al-fana' berasal dari kata faniya yang berarti musnah atau lenyap, keadaan dari Syai' (sesuatu) yang tidak berakhir, artinya apabila tetapnya suatu keadaan telah berakhir, dikatakan bahwa ia telah mencapai fana, ${ }^{39}$

Dalam hal ini Abu Bakar Al-Kalabadzi (w. 378 H / 988 M) mendefinisikannya: "hilangnya semua keinginan hawa nafsu seseorang, tidak ada pamrih dari segala kegiatan manusia, sehingga ia kehilangan segala perasaannya dan dapat membedakan sesuatu secara sadar, dan ia telah menghilangkan semua kepentingan ketika berbuat sesuatu". 40

Al-Fana dalam pengertian umum sebagaimana dikutip oleh Siregar dapat dilihat dari penjelasan al-Junaidi, ${ }^{41}$ yaitu :

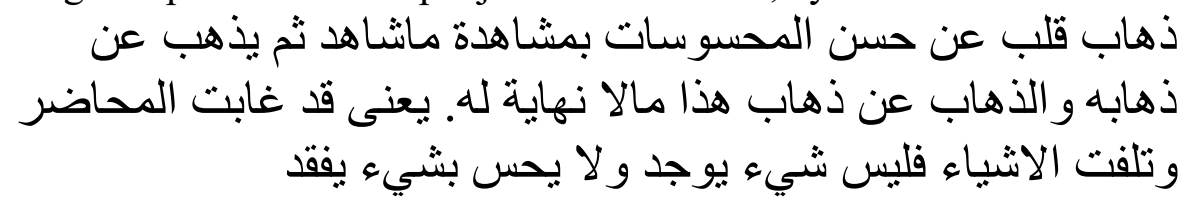

Artinya:

Hilangnya daya kesadaran qalbu dari hal-hal yang bersifat inderawi karena adanya sesuatu yang dilihatnya. Situasi yang demikian akan beralih karena hilangnya sesuatu yang terlihat itu dan berlangsung terus secara slilih berganti sehingga tiada lagi yang disadaridan dirasakan oleh indera.

Sebelum sampai kepada al-ittihad seorang sufi terlebih dahulu menghancurkan dirinya, selama ia belum dapat menghancurkan dirinya, ia tidak dapat bersatu dengan Tuhan. Itu sebabnya al-fana' sebagai proses awal lalu kemudian dilanjutkan dengan al-baqa yang

${ }^{39}$ Khan Shahib Khaja, Studies In Tasawuf (terjemah), (Jakarta, Raja Grafindo Persada, 1993), h. 91.

${ }^{40}$ Abdul Hadi WM, Tasawuf Yang Tertindas (Jakarta: Paradigma, 2001), h. 44

${ }^{41}$ Rivay Siregar, Tasawuf dari Sufisme Klasik ke Neo-Sufisme, (Jakarta: PT Raja Grafindo Persada, 2002), h. 147 
satu dengan yang lain merupakan kembar yang tidak dapat dipisahkan. Yang dimaksud dengan hancurnya jiwa suci bukan berarti hilang, tetapi kehancuran yang akan menimbulkan kesadaran sufi terhadap dirinya. Kesadaran ini disebut dengan al-fana 'alan nafs wa al baqa' billah, yaitu kesadaran tentang diri sendiri hancur dan timbulah kesadaran diri Tuhan. Dengan terjadinya fana otomatis baqa akan datang sendiri dalam kondisi seperti itu ittihad pun terjadi pula. Abu Yazid membawa pengertian yang berbeda dengan Junaid khususnya dalam masalah sakar, yaitu mabuk dalam mencintai Tuhan. ${ }^{42}$

Abu Yazid al-Bustami berpendapat bahwa manusia hakikatnya se-esensi dengan Allah, dapat bersatu dengan-Nya apabila ia mampu melebur eksitensi keberadaan-Nya sebagai suatu pribadi sehingga ia tidak menyadari dirinya (fana an nafs). ${ }^{43}$

Apabila seorang sufi telah sampai kepada fana'al-nafs yaitu tidak disadarinya wujud jasmaniyah, maka yang tinggal adalah wujud rohaniahnya dan ketika itu ia bersatu dengan Tuhan secara ruhani.

Dari berbagai uraian tersebut diketahui bahwa yang dituju dengan al-fana'dan al-baqa'adalah mencapai persatuan secara rohaniah dan bathiniah dengan Tuhan, sehingga yang disadarinya hanya Tuhan dalam dirinya. Dengan demikian materi manusianya tetap ada, sama sekali tidak hancur, demikianlah juga alam sekitarnya, yang hilang atau hancur hanya kesadaran dirinya sebagai manusia, ia tidak lagi merasakan jasad kasarnya.

Seorang sufi yang telah sampai pada tingkat makrifat berarti telah dekat dengan Allah; bertambah diri tingkatannya dalam makrifat, bertambah pula dekatnya dengan Allah sehingga bersatu dengan-Nya istilah tasawuf disebut al-Ittihad. akan tetapi sebelum ia bersatu dengan Allah, terlebih dahulu ia harus menghancurkan diri, yang disebut al-fana'. Penghancuran diri itu selalu diiringi dengan albaqa'. Baqa dan fana dapat diibaratkan dengan dua sisi dari satu mata uang sama.

2. Al-Hulul

Hulul secara leksikal merupakan kata benda abstrak (masdar) yang diderivisikan dari kata (حل يحل حلا) lalu di-Indonesia-kan

\footnotetext{
${ }^{42}$ Duski Samad, Studi Tasawuf Sejarah Tokoh dan Pemikiranya, (Padang: 2004, t.p. Mengutip dari : Muhammad Ghalab, Tasawuf Al-Muqarin, (Kairo, Maktabah Nahdah, t.t.), h. 192-193.

${ }^{43}$ Rifai Siregar, Tasawuf dari Sufisme Klasik ke Neo-Sufisme, h. 147.
} 
menjadi menempati, bertempat tinggal bahkan dalam bentuk plus alifnun (حلاة) ia dapat berarti luluh atau larut menyatu. ${ }^{44}$

Pengertian al-hulul secara singkat adalah Tuhan mengambil tempat dalam tubuh manusia tertentu, yaitu manusia yang telah dapat membersihkan dirinya dari sifat-sifat kemanusiaan melalui fana atau eksate.Sebab menurut Al-Halaj, manusia mempunyai sifat dasar yang ganda, yaitu sifat ketuhanan atau lahut dan sifat insani atau nasut. Demikian juga Tuhan memiliki sifat ganda yaitu sifat-sifat Ilahiyat atau lahut dan sifat insaniyah atau nasut. Apabila seseorang telah menghilangkan sifat kemanusiaanya dan mengembangkan sifat-sifat Ilahiyatnya melalui fana, Maka Tuhan akan mengambil tempat dalam dirinya dan terjadilah kesatuan antara manusia dengan Tuhan dan inilah yang dimaksud dengan hulul.

Teori lahut dan nasut ini, berangkat dari pemahamanya tentang proses kejadian manusia. Al-Halaj berpendapat bahwa Adam sebagai manusia pertama diciptankan Tuhan sebagai copy dari diri-Nya surah min nafsih dengan segenap sifat dan kebesaranya. ${ }^{45}$

Meskipun demikian terdapat perbedaan al-Hulul dengan ittihad yaitu dalam hulul, jasad tidak lebur sedangkan dalam ittihad dalam diri lebur dan yang ada hanya diri Allah, dan dalam ittihad yang dilihat hanya satu wujud dan dalam hulul ada dua wujud yang bersatu dalam satu tubuh.

\section{Wahdat al-Wujud}

Wahdat al-Wujud (kesatuan wujud). Menurut Ibn 'Arabi, wujud semua yang ada ini hanyalah satu dan pada hakikatnya wujud mahluk adalah wujud Khalik pula. Tidak ada perbedaan antara keduanya (Khalik dan makhluk) dari segi hakikat. Adapun kalau ada yang mengira adanya perbedaan wujud Khalik dan mahluk, hal itu dipandang dari panca indra lahir dan akal yang terbatas kemampuannya dalam menangkap hakikat apa yang ada pada zat-Nya dari kesatuan zatiyyah, yang segala sesuatu terhimpun pada-Nya. Hal ini tersimpul dalam ucapan Ibn 'Arabi berikut ini:

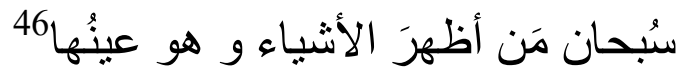

Artinya:

\footnotetext{
${ }^{44}$ Duski Samad, Studi Tasawuf Sejarah Tokoh dan Pemikiranya, (Padang: 2004, t.p.),h. 186

${ }^{45}$ Q.S. al-Nisa' (4):1; Q.S. al-An'am (6):98;Q.S. al-A'raf (8):189; dan Q.S. al-Zumar(39):6.

${ }^{46}$ Ibn 'Arabi, al-Futuhah al-Makkiyya, Jilid II (Bairut: Dar Sadir, t.th.), h. 604.
} 
Maha Suci Tuhan yang telah menjadikan segala sesuatu dan Dia sendiri adalah hakikat segala sesuatu itu.

Menurut paham ini tidak ada pencipta dan makhluk, karena semua adalah makhluk dan semua adalah Tuhan. Dia berkata :

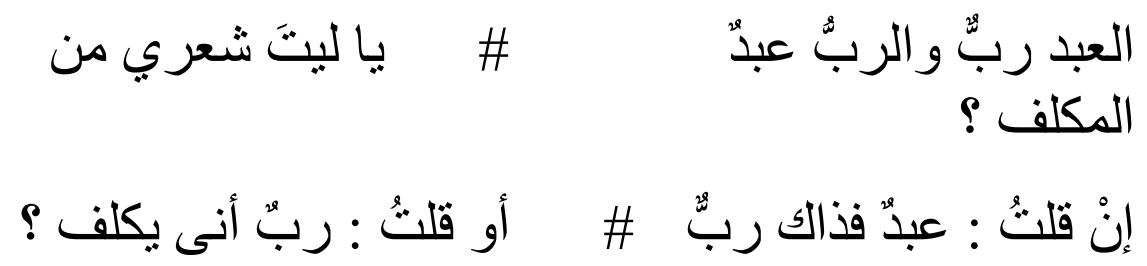

Hamba adalah Tuhan dan Tuhan adalah hamba \# Aduhai andai aku tahu siapa yang mukallaf? Jika saya mengatakan hamba maka dia adalah Tuhan \# Jika saya mengatakan Tuhan bagaimana mungkin dia menjadi mukallaf ? ${ }^{47}$

Paham ini mengajarkan bahwa manusia dengan Tuhan satu, yang dicintai dan mencintai satu, yang dilahat adalah satu wajud, walaupun pada hakikatnya dua wujud yang terpisah. Paham ini dipopulerkan Abu Yazid al Bustani dimana dia mengatakan bahwa sebelum sorang sufi menyatu harus fana dan baqa terlebih dahulu dan setelah itu baru menyatu dengan Tuhan, dan setelah menyatu sering keluar ucapan-ucapan yang tidak dimengerti oleh orang lain yang disebut Syatahat.

\section{Kesimpulan}

Ajaran Sufi muncul pertama kali di Bashrah Irak karena negeri tersebut terkenal dengan ulamanya yang zuhud, dimana kemunculan paham ini dilatarbelakangi oleh faktor lingkungan, adanya penyimpanagan dalam beragama, pengaruh agama Persia, dan pengembangan terhadap agama klasik. Hakikat Sufi adalah sebuah proses pendekatan hamba kepada sang Khalik dengan melalui beberapa tahapan, yaitu: al-maqāmāt dan hāl, di mana kedua tahapan ini di aplikasikan dalam bentuk: at-Takhalli, Tahalli, dan at-Tajalli dengan menggunakan metode: Riyadhah, Tafakkur, Tazakkur, dan Tazkiyatunnafs. Bila seorang sufi melalui semua tahapan-tahapan ini, maka ia akan mencapai puncak kulminasi yang disebut dengan: alFana, al-Baqa, al-Ittihad, al-Hulul, dan Wihdatul Wujud.

\section{Daftar Pustaka}

\footnotetext{
47 Muhammad bin Jamil Zainu, h. 9
} 
Syekh Abdul Qadir al-Jailani, Sirr al-Asrar, diterjemahkan ke dalam bahasa Indonesia oleh Joko S. Kahar dengan judul Rahasia di Balik Rahasia, Cet. 3; Surabaya: Risalah Gusti, 2003.

Muhammad bin Ismail bin Abu Abdillah al-Bukhari al-Ja'fi, Al-Jami' al-Sahih, Jilid 6, Bairut: Dar Ibn Kasir al-Yamamah, 1407 H/1987 M.

Amin Syukur, Menggugat Tasawuf, Sufisme dan Tanggung Jawab Sosial Abad 21, Cet. 2; Yogyakarta: Pustaka Pelajar, 2002.

Faisal Badir 'Aun, al-Tasawwuf al-Islami al-Tariq wa al-Rijal, Cairo: Maktabah Sa'id Ri'fat, 1983.

Yusuf Muhammad Zaidan, al-Tariq al-Sufi wa Furu' al-Qadiriyah bin Misr, Cet. 1; Beirut: Dar al-Jeil, 1991.

Ensiklopedi Islam, Jilid 3, Jakarta: PT. Ihtiar Baru Van Hoeve, 1994.

Harun Nasution, Falsafah dan Mistisme dalam Islam, Cet. 9; Jakarta: Bulan Bintang, 1995.

Simuh, Tasawuf dan Perkembangannya dalam Islam, Cet. 1; Jakarta: PT. Raja Grafindo Persada, 1996.

Muhammad bin Ismail bin Abu Abdillah al-Bukhari al-Ja'fi, Al-Jami' al-Sahih, Jilid 5, Bairut: Dar Ibn Kasir al-Yamamah, 1407 H/1987 M.

Media Zainul Bahri, Menembus Tirai Kesendirian-Nya; Mengurai Maqāmāt dan Ahwal dalam Tradisi Sufi, Cet. 1; Jakarta: Prenada, 2005.

Ibnu Qayyim al-Jauziyah, al-Faruqun Nafisah baina Sifsatinnafsi alTayyibah wa al-Khabisah. Diterjemahkan oleh Abu Ahmad Najieh dengan judul Etika Kesucian: Wacana Penyucian Jiwa, Entitas sikap hidup Muslim, Cet. 1; Surabaya: Risalah Gusti, 1998.

Abi Qasim Ab al-Karim bin Hauzan al-Qusairi, al-Risalah alQusairiyyah, Cet. 5; Baeirut: Dar al-Kutub al-Ilmiyyah, 2005.

Muhammad bin Isma'il abu Abdullah al-Bukhari al-Ja'fi, al-Jami' alSahih al-Mukhtasar, Jilid 5, Bairut: Dar Ibn Kasir, 1407 H/1987 M.

Mustafa Zahri, Kunci Memahami Ilmu Tasawuf, Surabaya: PT. Bina Ilmu, t.th. 
Hassan Hanafi, Islam in Modern World, diterjemahkan oleh Munirul Abidin dengan judul Rekonstruksi Pemahaman Tradisi Islam Klasik, Cet. 1; Malang: Kutub Minar, 2004.

Tim Penyusun MKD Iain Sunan Ampel Surabaya, Akhlak Tasawuf, Surabaya: IAIN Sunan Ampel Pres. 2011.

Abd al-Razzaq al-Kasyani, Mu’jam istilahat al-Sufiyah, Cet. 1; Cairo:Dar al-Manar, 1992.

Al-Ghazali, Risalah al-Ladunniyah, Jilid I, Mesir:Maktabah al-Jundi, 1970.

Khan Shahib Khaja, Studies In Tasawuf (terjemah), Jakarta, Raja Grafindo Persada, 1993.

Abdul Hadi WM, Tasawuf Yang Tertindas, Jakarta: Paradigma, 2001.

Rivay Siregar, Tasawuf dari Sufisme Klasik ke Neo-Sufism, Jakarta: PT Raja Grafindo Persada, 2002.

Duski Samad,. Mengutip dari: Muhammad Ghalab, Tasawuf AlMuqarin, Kairo, Maktabah Nahdah, t.t.

Duski Samad, Studi Tasawuf Sejarah Tokoh dan Pemikiranya, (Padang: 2004, t.p.

R.A. Nicholson, The Mystic Of Islam, Routledge \& Kegan Paul: London, 1996.

Ibn 'Arabi, al-Futuhah al-Makkiyya, Jilid II, Bairut: Dar Sadir, t.th. 